\title{
Species-specific responses to ocean acidification should account for local adaptation and adaptive plasticity
}

\author{
Cristian A. Vargas ${ }^{1,2,3 \star}$, Nelson A. Lagos ${ }^{3,4}$, Marco A. Lardies ${ }^{3,5}$, Cristian Duarte ${ }^{3,6}$, Patricio H. Manríquez, \\ Victor M. Aguilera ${ }^{2,8}$, Bernardo Broitman ${ }^{3,7}$, Steve Widdicombe ${ }^{9}$ and Sam Dupont ${ }^{10}$
}

\begin{abstract}
Global stressors, such as ocean acidification, constitute a rapidly emerging and significant problem for marine organisms, ecosystem functioning and services. The coastal ecosystems of the Humboldt Current System (HCS) off Chile harbour a broad physical-chemical latitudinal and temporal gradient with considerable patchiness in local oceanographic conditions. This heterogeneity may, in turn, modulate the specific tolerances of organisms to climate stress in species with populations distributed along this environmental gradient. Negative response ratios are observed in species models (mussels, gastropods and planktonic copepods) exposed to changes in the partial pressure of $\mathrm{CO}_{2}\left(p_{\mathrm{CO}_{2}}\right)$ far from the average and extreme $\boldsymbol{p}_{\mathrm{CO}_{2}}$ levels experienced in their native habitats. This variability in response between populations reveals the potential role of local adaptation and/or adaptive phenotypic plasticity in increasing resilience of species to environmental change. The growing use of standard ocean acidification scenarios and treatment levels in experimental protocols brings with it a danger that inter-population differences are confounded by the varying environmental conditions naturally experienced by

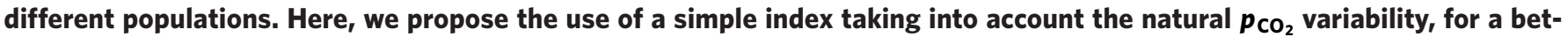
ter interpretation of the potential consequences of ocean acidification on species inhabiting variable coastal ecosystems. Using scenarios that take into account the natural variability will allow understanding of the limits to plasticity across organismal traits, populations and species.
\end{abstract}

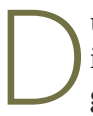
uring the past two centuries, human activities exerted a growing influence over the global climate system, mostly through greenhouse gas emissions and chiefly $\mathrm{CO}_{2}$ derived from burning fossil fuels ${ }^{1,2}$. This increasing global footprint of human activities on the biosphere has led some to use the term 'the Anthropocene', to denote the present period of anthropogenically induced global environmental change ${ }^{3}$. The ongoing oceanic absorption of atmospheric $\mathrm{CO}_{2}$ has helped to restrict present global warming by reducing the total amount of manmade $\mathrm{CO}_{2}$ in the atmosphere. However, this massive oceanic uptake of $\mathrm{CO}_{2}\left(28 \%\right.$ of anthropogenic $\mathrm{CO}_{2}$ emissions since the 1970s) has altered carbonate chemistry cycles in the global ocean, disturbing its delicate geochemical balance ${ }^{4}$. This disruption of carbonate chemistry processes, known collectively as ocean acidification, has been of great scientific interest and of growing public concern ${ }^{5}$. Ocean acidification has been one of the most studied scientific topics in marine science worldwide for the past 15 years $^{6}$, a period during which this topic has reached both the public and political spheres. Nowadays, it is well known that conditions of low $\mathrm{pH} /$ high partial pressure of $\mathrm{CO}_{2}\left(p_{\mathrm{CO}_{2}}\right)$ can impact marine organisms, from molecular, physiological, developmental and behavioural processes, all the way to species interactions at the ecosystem level ${ }^{7,8}$. Scientists have now conducted many different ocean acidification experiments on a variety of marine species, usually exposing these organisms over short- or mid-term periods to experimental conditions based on scenarios modelled for oceanic waters ${ }^{9}$, typically simulating present (for example, $400 \mu \mathrm{atm}$ ) and near-future ocean $p_{\mathrm{CO}_{2}}$ levels (for example, 650, 750 and/or $1,000 \mu \mathrm{atm})^{10}$. Through this experimental approach, a variety of different biological responses have been studied, including photosynthesis, growth, ingestion, calcification, reproduction, behaviour, gene expression and biological interactions, among others ${ }^{11}$.

The application of standard exposure scenarios was proposed to facilitate comparison between studies ${ }^{10}$ and was based on those changes expected to occur in the surface open ocean. However, most marine species studied largely inhabit highly variable coastal environments, such as coral reefs, intertidal, sandy or rocky shores, upwelling zones, estuaries or fjords, salt marshes and so on, where $\mathrm{pH} / \mathrm{p}_{\mathrm{CO}_{2}}$ levels vary far more dramatically over different temporal and spatial scales than in open ocean environments ${ }^{12}$. Such variability results from a number of natural and anthropogenic coastal processes such as river discharges, upwelling, ice melting, eutrophication, pollution and so on ${ }^{13-15}$. Indeed, many nearshore areas experience intense $\mathrm{pH} / \mathrm{p}_{\mathrm{CO}_{2}}$ fluctuations, with levels of variability often being significantly higher than would be expected if driven solely

\footnotetext{
'Department of Aquatic Systems, Faculty of Environmental Sciences, Universidad de Concepción, Concepción, 4030000, Chile. ${ }^{2}$ Millennium Institute of Oceanography (IMO), Universidad de Concepción, Concepción, 4030000, Chile. ${ }^{3}$ Center for the Study of Multiple-Drivers on Marine Socio-Ecological Systems (MUSELS), Universidad de Concepción, Concepción, 4030000, Chile. ${ }^{4}$ Centro de Investigación e Innovación para el Cambio Climático (CiiCC), Facultad de Ciencias, Universidad Santo Tomás, Santiago, 8320000, Chile. ${ }^{5}$ Facultad de Ingeniería and Facultad de Artes Liberales, Universidad Adolfo Ibáñez, Santiago, 8320000, Chile. ' Departamento de Ecología y Biodiversidad, Facultad de Ecología y Recursos Naturales, Universidad Andrés Bello, Santiago, 8320000, Chile. ${ }^{7}$ Centro de Estudios Avanzados en Zonas Áridas (CEAZA), Universidad Católica del Norte, Coquimbo, 1780000, Chile. ${ }^{8}$ Instituto de Ciencias Naturales Alexander von Humboldt, Universidad de Antofagasta, Antofagasta, 1240000, Chile. ${ }^{9}$ Plymouth Marine Laboratory (PML), Plymouth PL13DH, UK. ${ }^{10}$ Department of Biological \& Environmental Sciences, University of Gothenburg, Gothenburg 69318, Sweden. *e-mail: crvargas@udec.cl
} 


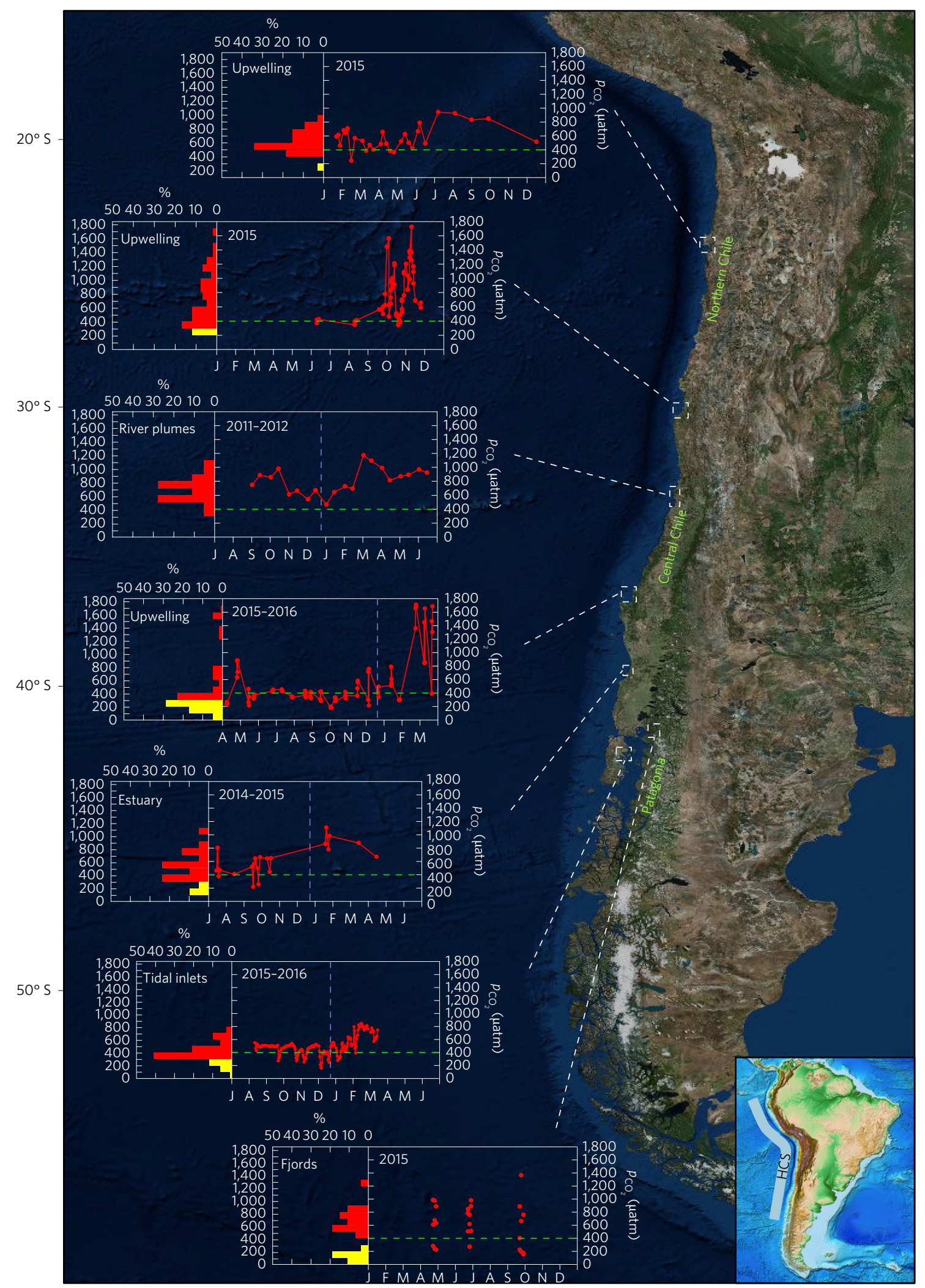

Figure 1 | Temporal series (line plots) and frequency analysis (bars plots) of surface (upper $10 \mathrm{~m}$ depth) $p_{\mathrm{CO}_{2}}$ ( $\mu$ atm) for different coastal environments along the Chilean coast. Analysis was based on research cruises, field-monitoring programmes and buoys deployed in different coastal stations (see Supplementary Material 1). The green dashed line in the temporal series represents the $p_{\mathrm{CO}_{2}}$ level of $400 \mu$ atm, the baseline level used as a control in most ocean acidification experiments. Dashed blue vertical lines represent the end of the respective year. Yellow bars in the frequency analysis correspond to frequency ranges $<400 \mu \mathrm{atm}$. Red bars highlight those $p_{\mathrm{CO}_{2}}$ frequency ranges higher than $400 \mu \mathrm{atm}$. Letters along the $x$ axis represent months from January to December. Base map from Trackline Geophysical Data, National Centers for Environmental Information, NOAA (https://maps.ngdc.noaa.gov/ viewers/geophysics/). 
by a process of equilibration with the atmosphere ${ }^{16,17}$. This diversity of causative drivers and the high degree of variability in coastal environments, when compared with open ocean systems, limits the direct extrapolation of ocean acidification concepts and scenarios between these different environments ${ }^{18}$. In addition, this environmental variability can drive associated local adaptation, which can also play a key role in setting sensitivity of a species to changes in $\mathrm{pH} / p_{\mathrm{CO}_{2}}$. For example, the precise physiological ${ }^{19,20}$ and evolutionary processes ${ }^{21}$ involved can be different depending on whether experimental scenarios are within or outside of the natural range of variability experienced by that organism.

To be able to project how future ocean acidification will affect marine organisms, populations and ecosystems, it is therefore necessary to monitor present day $\mathrm{pH} / p_{\mathrm{CO}_{2}}$ conditions ${ }^{16,22,23}$ and design relevant ocean acidification experimental scenarios accordingly. Surprisingly, many scientists continue to expose coastal species to ocean acidification scenarios derived for the open ocean ${ }^{24}$. In doing so, the baseline or control conditions chosen can be unrepresentative of the organism's normal environment experienced in the field, with generally lower, more stable levels of $p_{\mathrm{CO}_{2}}$ than the organism is used to. Assessments of the effects of $\mathrm{pH} / \mathrm{p}_{\mathrm{CO}_{2}}$ using such unrealistic scenarios do not represent realistic future projections and often treatments aimed at simulating future conditions actually represent an organism's present condition. Consequently, many previous experiments are more likely to have given us insights about the generic role of $\mathrm{pH} / \mathrm{P}_{\mathrm{CO}_{2}}$ levels as a natural environmental driver, than the likely impacts of elevated levels of $\mathrm{CO}_{2}{ }^{17}$. This has significant implications for meta-analyses and experimental designs, which should take into account the deviation of $\mathrm{CO}_{2}$ conditions from a natural range of variability rather than a single assumed control pH/ $p_{\mathrm{CO}_{2}}$ level.

Here, we conducted a meta-analysis of different studies focused on determining the reaction norm, that is, the range of phenotypes expressed by a given population as a function of environmental variation ${ }^{25}$, under high $p_{\mathrm{CO}_{2}}$ conditions, for different local populations of marine organisms (mussels, gastropods and planktonic copepods) inhabiting contrasting coastal environments along the Humboldt Current System (HCS) off Chile. These experimental results were contrasted with local $p_{\mathrm{CO}_{2}}$ data available for the different environments from where experimental organisms were collected. Using these insights, we propose the use of a simple index taking into account natural $p_{\mathrm{CO}_{2}}$ variability, to shed light on the interpretation of experiments focused on understanding the potential consequences of ocean acidification on species inhabiting coastal ecosystems.

\section{Results and discussion}

$\boldsymbol{p}_{\mathrm{CO}_{2}}$ environmental variability. Figure 1 shows the temporal series and frequency analysis of surface (upper $10 \mathrm{~m}$ depth) $p_{\mathrm{CO}_{2}}$ ( $\mu \mathrm{atm})$ for different and contrasting coastal environments along the Chilean coast. Contrasting spatial patterns arise when comparing the $p_{\mathrm{CO}_{2}}$ frequency distribution among sites. Episodic events of extremely high $p_{\mathrm{CO}_{2}}$ levels are observed in upwelling areas off central to northern Chile $\left(30-40^{\circ} \mathrm{S}\right)$, with values up to $\sim 1,800 \mu \mathrm{atm}$. Despite the low sampling frequency, river plume areas display persistently high $p_{\mathrm{CO}_{2}}$ conditions $(>450 \mu \mathrm{atm})$, where the resident marine biota are exposed chronically to acidic waters, mostly resulting from the export of organic and inorganic carbon from the watershed to the ocean ${ }^{26}$. Seasonal differences are observed along the latitudinal range, with unimodal distributions in the northern region, whereas in higher latitudes, different processes drive bi-modal frequency distributions. Among these processes are the strong seasonal effects, due to differences in phytoplankton productivity (that is, winter versus spring/summer) and therefore $p_{\mathrm{CO}_{2}}$ uptake (for example, estuarine and tidal inlets; Fig. 1). In general, the vertical structure of $p_{\mathrm{CO}_{2}}$ in the upper $10 \mathrm{~m}$ depth is characterized by relatively similar values, especially for upwelling areas. However, stratification owing to freshwater runoff in estuarine waters, river plumes and river-influenced fjords drives differences in $p_{\mathrm{CO}_{2}}$ levels between surface (1-5 $\mathrm{m}$ depth) and subsurface (5-10 $\mathrm{m}$ depth) waters, resulting in bi-modal frequency distributions (Fig. 1). In southern Patagonia, tidal inlets and river-influenced fjord regions

Table 1 | Intraspecific variability in the physiological responses of different taxa collected in environments with naturally contrasting $\mathrm{pCO}_{2}$ levels on laboratory exposition to low $\mathrm{pH} / \mathrm{high} \mathrm{p}_{\mathrm{CO}_{2}}$ levels.

\begin{tabular}{|c|c|c|c|c|c|c|c|c|c|c|}
\hline Group & Taxon & $\begin{array}{l}\text { Life } \\
\text { stage }\end{array}$ & Environment & 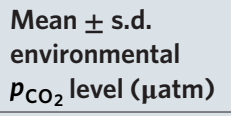 & $\begin{array}{l}\text { Control } \\
\text { level } p_{\mathrm{CO}_{2}} \\
\text { ( } \mu \text { atm) }\end{array}$ & $\begin{array}{l}\text { Experimental } \\
\text { level } p_{\mathrm{CO}_{2}} \\
(\mu \text { atm) }\end{array}$ & Response & $\begin{array}{l}\text { Mean } \\
\text { effect } \\
(\%)\end{array}$ & $n$ & Reference \\
\hline Gastropod & C. concholepas & $J$ & Coastal ocean & $555.6 \pm 157.5$ & 380 & 1,500 & Respiration & $+213^{\dagger}$ & 30 & 29 \\
\hline Gastropod & C. concholepas & $J$ & Estuarine & $623.42 \pm 233.68$ & 380 & 1,500 & Respiration & $+147^{\dagger}$ & 30 & 29 \\
\hline Gastropod & C. concholepas & VL & Coastal ocean & $555.6 \pm 157.5$ & 376 & $980-1100$ & Ingestion & $-47^{\star}$ & 180 & 30 \\
\hline Gastropod & C. concholepas & VL & Estuarine & $623.42 \pm 233.68$ & 376 & $980-1,100$ & Ingestion & $-33^{\star}$ & 180 & 30 \\
\hline Gastropod & C. concholepas & VL & River-plume area & $811.0 \pm 185.7$ & 376 & $980-1,100$ & Ingestion & -17 & 180 & 30 \\
\hline Gastropod & C. concholepas & $\mathrm{VL}$ & Estuarine & $623.42 \pm 233.68$ & $365-398$ & $979-1,077$ & Larval survival & $-60^{\star}$ & 120 & 44 \\
\hline Gastropod & C. concholepas & $\mathrm{VL}$ & River-plume area & $811.0 \pm 185.7$ & $365-398$ & $979-1,077$ & Larval survival & -17 & 120 & 44 \\
\hline Mussel & P. purpuratus & $A$ & Estuarine & $623.42 \pm 233.68$ & $347-377$ & $910-960$ & Ingestion & $-60^{\star}$ & 30 & 30 \\
\hline Mussel & P. purpuratus & A & River-plume area & $811.0 \pm 185.7$ & $347-377$ & $910-960$ & Ingestion & -13 & 30 & 30 \\
\hline \multirow[t]{2}{*}{ Mussel } & M. chilensis & $J$ & Tidal inlet & $500.8 \pm 140.2$ & 388 & 979 & Calcification & $-37^{\star}$ & 30 & 31 \\
\hline & & & & & & & Growth & $-35^{\star}$ & & \\
\hline \multirow[t]{2}{*}{ Mussel } & M. chilensis & $J$ & $\begin{array}{l}\text { Freshwater-influenced } \\
\text { tidal inlet }\end{array}$ & $608.9 \pm 319.3$ & 388 & 979 & Calcification & -4 & 30 & 31 \\
\hline & & & & & & & Growth & -13 & & \\
\hline Copepod & A. tonsa & A & Coastal ocean & $405.9 \pm 95.4$ & $398-405$ & 1,255 & Ingestion & $-72^{\star}$ & 36 & 43 \\
\hline Copepod & A. tonsa & A & Estuarine & $623.42 \pm 233.68$ & $398-405$ & 1,255 & Ingestion & +5 & 36 & 43 \\
\hline
\end{tabular}

Different life stages were considered in these studies (A, adults; J, juveniles; VL, veliger larvae). ${ }^{\star}$ Negative mean effects higher than $30 \%$ in high $p \mathrm{CO}_{2}$ treatments in comparison with control treatments. Positive mean effects on high $p \mathrm{CO}_{2}$ conditions. $n$, sample size; s.d., standard deviation. 
can also experience frequent periods where $p_{\mathrm{CO}_{2}}$ levels are higher than atmospheric levels ( $>400 \mu \mathrm{atm})$. We used an autocorrelation analysis (Supplementary Fig. 1) to compare the two time series in our data set, which had the longest period of daily records (see Fig. 1), one from the northern upwelling area and the other from a tidal inlet. This analysis showed that $p_{\mathrm{CO}_{2}}$ levels fluctuated over shorter temporal scales in the upwelling region in contrast to the tidal inlet, where $p_{\mathrm{CO}_{2}}$ levels were more stable. These data illustrated that the use of average atmospheric $p_{\mathrm{CO}_{2}}$ level is not appropriate when establishing the baseline conditions for ocean acidification experiments on near-surface-dwelling ( $<10 \mathrm{~m}$ depth) marine organisms in either of these different coastal environments (Fig. 1). To include this natural variability in an experimental design, several treatments should be included, covering present and future natural variability ${ }^{19}$. Moreover, the variability on different timescales can also play a key role in modulating the species response and should therefore be included.

Adaptive responses. Evaluating experimentally how marine organisms with multi-year generation times will respond to changes in physical-chemical conditions over long timescales can be extremely difficult. Comparative studies using species with geographic ranges spanning large environmental gradients in $\mathrm{pH} / \mathrm{p}_{\mathrm{CO}_{2}}$ may help us to understand how long-term adaptation to different environments can modulate individual sensitivity to additional stressors $^{27,28}$. However, there are few studies that have assessed how responses to changing $\mathrm{pH} / \mathrm{p}_{\mathrm{CO}_{2}}$ conditions vary among individuals (that is, within the same species) from geographically distant populations ${ }^{29-31}$. The heterogeneous coastal ecosystem across the long latitudinal range off Chile (more than $35^{\circ}$ and $6,000 \mathrm{~km}$ of coast) provides suitable conditions and a natural laboratory in which we can evaluate intraspecific variability in ocean acidification responses using individuals from different geographic areas and experiencing contrasting oceanographic regimes. This unique setting, in turn, has the potential to provide us with considerable insights into the responses that species may have under different ocean acidification scenarios along the Chilean coast.

An interesting result emerging from the comparison of conspecifics from habitats with different $p_{\mathrm{CO}}$ levels (for example, coastal versus estuarine areas and/or river-influenced areas) is the difference in the mean effects of experimentally elevated $p_{\mathrm{CO}_{2}}$ conditions. For instance, Acartia tonsa individuals from low $\mathrm{pH} /$ high $p_{\mathrm{CO}_{2}}$ estuarine waters are more tolerant to the same level of high $p_{\mathrm{CO}_{2}}$ than individuals from more oceanic populations (Table 1). $\mathrm{A} \mathrm{simi-}^{2}$ lar pattern can be observed when the intraspecific variability in the response to elevated $p_{\mathrm{CO}_{2}}$ is evaluated in veliger larvae, gastropods and mussels collected from contrasting habitats (Table 1).

The meta-analysis performed to evaluate the mean effects of elevated $p_{\mathrm{CO}_{2}}$ conditions on different physiological traits of the studied taxa indicated that individuals from areas naturally exposed to both high mean $p_{\mathrm{CO}_{2}}$ levels and high $p_{\mathrm{CO}_{2}}$ variability show null and/or lower mean negative effect on specific physiological traits, both for plankton (for example, copepod and veliger ingestion or veliger survival) and juvenile/adult molluscs (for example, mussel ingestion, calcification and growth, Fig. 2). Meanwhile, organisms from areas characterized by low variability and lower mean $p_{\mathrm{CO}_{2}}$ conditions show a significant negative effect when exposed to elevated $p_{\mathrm{CO}_{2}}$ on different traits, such as ingestion, survival, respiration, calcification and growth (Fig. 2). The negative effect of high $p_{\mathrm{CO}_{2}}$ levels was most pronounced for copepod ingestion, larval survival, gastropod respiration and mussel ingestion (Fig. 2). In consequence, we hypothesized that $\mathrm{pH} / \mathrm{p}_{\mathrm{CO}_{2}}$ constitutes an important and selective agent for physiological traits suiting local conditions of high environmental variability.

We devised an index aimed to estimate how far an organism has been exposed to conditions departing from its environmental
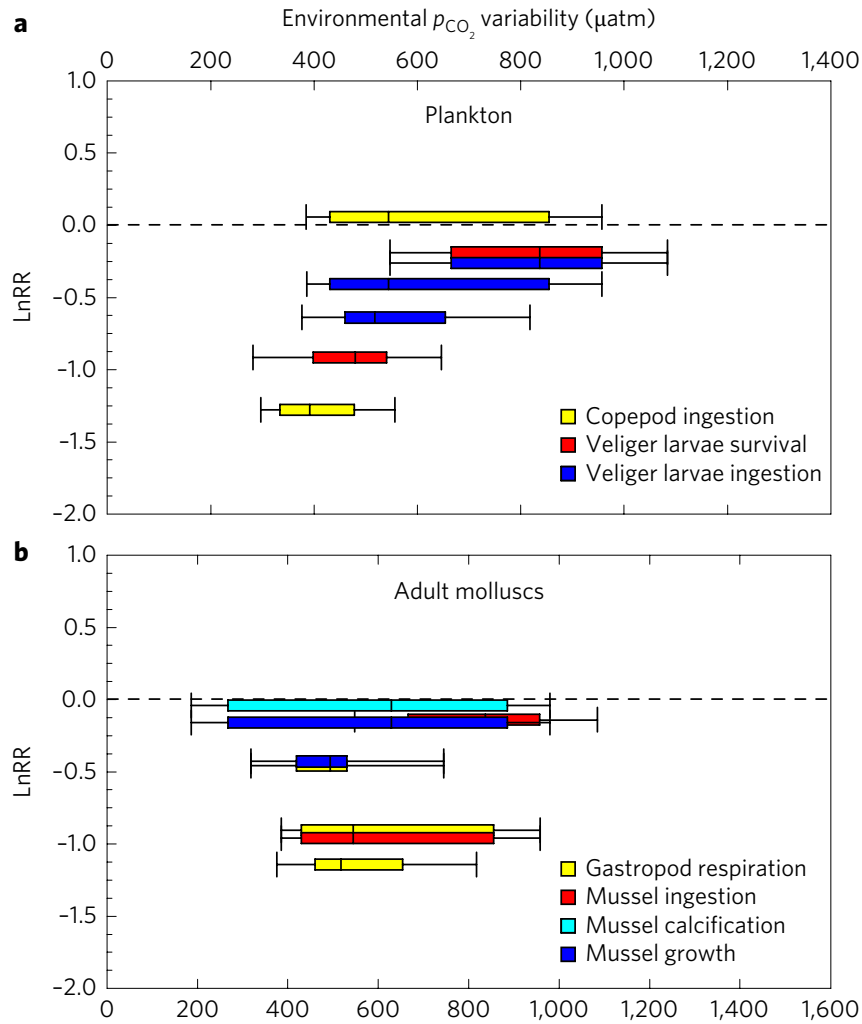

Figure 2 | The mean effect of near-future (2100) $\mathrm{CO}_{2}$-driven ocean acidification on different physiological traits in marine organisms. $\mathbf{a}, \mathbf{b}$, Box and whisker plots showing the median and range of environmental $p_{\mathrm{CO}_{2}}$ variability where experimental organisms from different geographic areas were collected versus the In-transformed response ratio (LnRR) in high $p_{\mathrm{CO}_{2}}$ level scenarios (910-1,500 $\mu$ atm). The relationship was analysed separately both for planktonic organisms (a) and marine molluscs (b).

range, represented as ' $\Delta p_{\mathrm{CO}_{2}}$ exposure' and based on the difference between the 'experimental high' $p_{\mathrm{CO}_{2}}$ level used in micro/mesocosm conditions and the mode of $p_{\mathrm{CO}_{2}}$ observations at each location. The relationship between the mean effect of high $p_{\mathrm{CO}_{2}}$ levels and the $\Delta p_{\mathrm{CO}_{2}}$ exposition indicated that marine organisms exposed to large changes in $p_{\mathrm{CO}_{2}}$ relative to the most frequent conditions found in their natural environment (that is, chronic exposure) showed the largest negative mean effect (Fig. 3a). This negative trend can be observed even within the same taxa, and suggests that increased tolerance to chronic high $p_{\mathrm{CO}_{2}}$ conditions might lead to an adaptive response. Such analysis can provide insight into how individuals at different points along an environmental gradient differ in their tolerance to high $p_{\mathrm{CO}_{2}}$ and/or low $\mathrm{pH}$ levels.

Extreme events play a disproportionately large role in shaping the physiology, ecology and evolution of organisms $s^{32,33}$. Therefore, we also estimated a $\Delta p_{\mathrm{CO}_{2}}$ exposition-as the difference between the 'experimental high' $p_{\mathrm{CO}_{2}}$ level used in micro/mesocosm conditions and the extreme or highest $p_{\mathrm{CO}_{2}}$ level recorded at each location on an annual basis-and then correlated this value with the experimental mean effect (Fig. 3b). Extreme high $p_{\mathrm{CO}_{2}}$ events were not necessarily observed in areas with the highest mode in the $p_{\mathrm{CO}_{2}}$ frequency analysis (Supplementary Fig. 2), therefore the significant negative correlation suggests that organisms such as juvenile and adult mussels from local populations exposed to extremely high $p_{\mathrm{CO}_{2}}$ levels $(>1,100 \mu \mathrm{atm})$ - even higher than exposed at the laboratory in the high $p_{\mathrm{CO}_{2}}$ treatment (i.e. negative $\Delta p_{\mathrm{CO}_{2}}$ )-experienced the lower mean effect. In consequence, environmental exposure to extremely high $p_{\mathrm{CO}_{2}}$ levels may have significant implications in the 


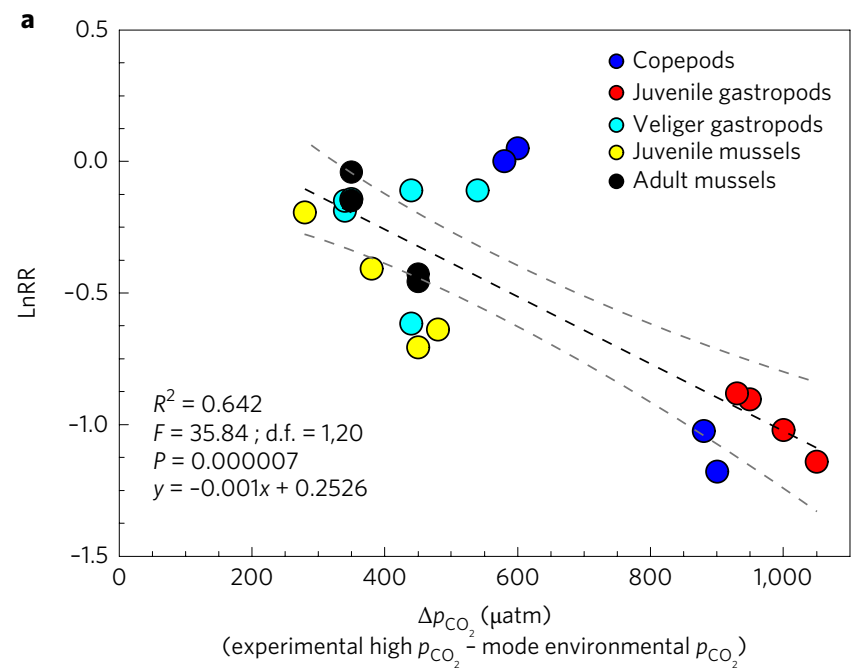

b

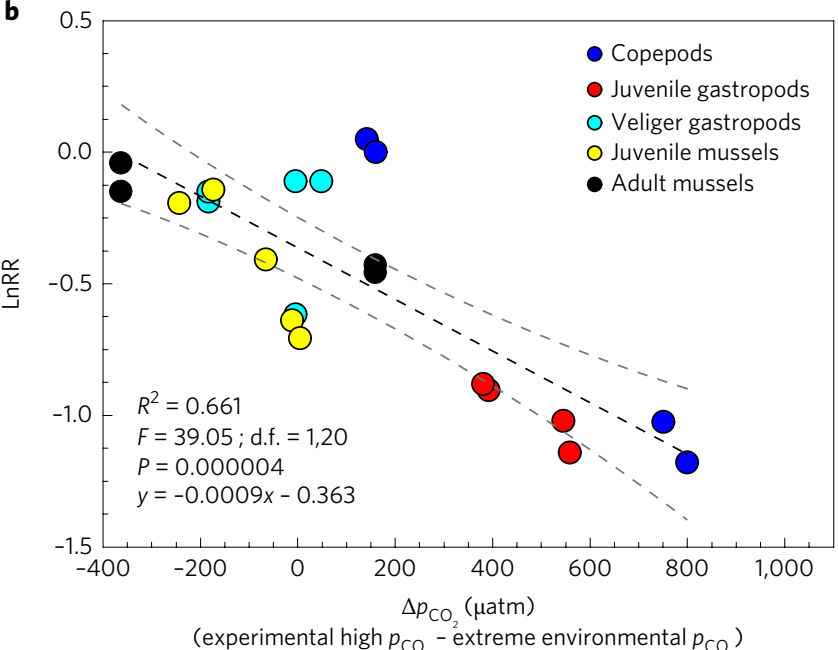

Figure 3 | Mean response of different marine taxa in relation to a $\Delta p_{\mathrm{CO}_{2}}$ level exposition. $\mathbf{a}, \mathbf{b}, \Delta \boldsymbol{p}_{\mathrm{CO}_{2}}$ ( $\mu \mathrm{atm}$ ) is represented as the difference between the experimental high $p_{\mathrm{CO}_{2}}$ level used in the corresponding mesocosms experiments less the mode in the frequency analysis of environmental $p_{\mathrm{CO}_{2}}(\mathbf{a})$ and/or the extreme $p_{\mathrm{CO}_{2}}$ level recorded at each local habitat (b). Black and grey lines represent the regression line and the $95 \%$ confidence interval, respectively. Inset shows the coefficient of determination $\left(R^{2}\right), F$ value, degrees of freedom (d.f.), $P$ value of the linear regression model and the estimated regression model.

selection of genotypes more resilient to high $p_{\mathrm{CO}_{2}}$ conditions and potential future ocean acidification conditions ${ }^{34}$.

The analysis of our results highlights that before experimentally evaluating $\mathrm{pH} / \mathrm{p}_{\mathrm{CO}_{2}}$ effects for coastal species it is necessary to firmly establish the natural $\mathrm{pH}$ conditions (average, variability) experienced at the location from which the organisms are sampled. This is critical to determine the most appropriate control and future ocean acidification scenarios, instead of exposing the organisms to a range of conditions that they may already be familiar with in nature ${ }^{35}$. Phenotypic responses are important for population persistence in changing environments ${ }^{36}$ and our understanding of the limits of plasticity must therefore be an important research goal when assessing the environmental challenges that the Anthropocene poses on marine organisms. The synthesis of published experimental information for the coastal sector of the HCS showed that populations of marine organisms from this highly heterogeneous environment harbour significant resilience, suggesting they have the potential to adapt to new niches and cope with the unprecedented selective processes posed by ocean acidification. However, because evolution is a multivariate process, to project future evolutionary pathways will require a deeper understanding of more phenotypic traits and their correlations with each other at the organism level ${ }^{37}$.

\section{Conclusions}

To better understand the potential impacts of ocean acidification on marine ecosystems, future studies should use realistic scenarios that consider the habitat-specific natural variability in seawater chemistry, particularly the patchiness in oceanographic conditions of coastal ecosystems. Therein, the lack of environmental data regarding $\mathrm{pH} / \mathrm{p}_{\mathrm{CO}_{2}}$ variability and geographic distributions of species are critical research gaps for studies dealing with the projection of organismal responses to ocean acidification. A large set of published experiments conducted with coastal marine species exposed to ocean acidification scenarios in the open ocean (that is, using $p_{\mathrm{CO}_{2}}$ levels predicted by the Intergovernmental Panel on Climate Change emission scenarios ${ }^{10}$ ) might have significantly underestimated the impact of ocean acidification on different physiological traits. This shortcoming is particularly relevant for species that may have inhabited low $\mathrm{pH} /$ high $p_{\mathrm{CO}_{2}}$ conditions throughout their evolution and bears major implications for the emphasis on neutral responses of benthic organisms when confronted with experimental ocean acidification conditions. Instead, a large body of research has probably explored the environmentally induced variation in selected phenotypic traits under natural $\mathrm{pH}$ variability and not their responses under the extreme scenarios posed by future and progressive ocean acidification. The simulation of scenarios that better represent both present and future $\mathrm{pH} / \mathrm{p}_{\mathrm{CO}_{2}}$ conditions will require a step change in how the ocean acidification experiments are designed, to improve understanding of how plasticity changes across organismal traits, populations and species, and how the obtained results can be interpreted, communicated and utilized elsewhere. Thus, we suggest that reporting the $\Delta p_{\mathrm{CO}_{2}}$ on the relevant spatial-temporal scale from natural conditions in any experiment using coastal species should become an accepted practice and would help those seeking to determine projected ocean acidification impacts at individual, population and ecosystem levels.

\section{Methods}

Study region. The HCS extends along the west coast of South America, from the Patagonian region in southern Chile (ca. $\sim 42^{\circ} \mathrm{S}$ ) up to Ecuador and the Galapagos Islands near the Equator $\left(\sim 5^{\circ} \mathrm{N}\right)$, and is one of the most productive marine ecosystems in the world ${ }^{38}$. This system, and particularly the coastal region off Chile, is characterized by large spatial-temporal heterogeneity in $p_{\mathrm{CO}_{2}}$ conditions ${ }^{39,40}$, and is an area in which the effects of low $\mathrm{pH} /$ high $p_{\mathrm{CO}_{2}}$ conditions can already be seen (Fig. 1). Moreover, one of the most striking biogeographic features of the Chilean coast is its large latitudinal extent, covering almost $6,000 \mathrm{~km}$ and containing extremely diverse marine habitats. These habitats range from the almost straight coastline in central and northern Chile (from $18^{\circ} 20^{\prime}$ to $41^{\circ} 45^{\prime} \mathrm{S}$ ) to a highly fragmented coast with a large number of islands, tidal inlets, channels and fjords in the Patagonia region (down to ca. $56^{\circ} \mathrm{S}$ ), which includes many calving glaciers and massive rivers draining the largest ice field outside the polar regions. Almost all of the different natural processes that contribute to temporal variability in coastal zone carbonate chemistry can be found at some point in this region, including variable photosynthesis/respiration ratio, wind-driven coastal upwelling, riverine discharges and ice melting ${ }^{39}$.

Data compilation on $\boldsymbol{p}_{\mathrm{CO}_{2}}$ variability in coastal environments. During the past five years, several observation programmes focussing on ocean acidification have been carried out along the Chilean coast. Most observational data come from regular monitoring programmes (on a biweekly, weekly and/or monthly basis) ${ }^{26,41}$, buoys deployed in specific regions (this study) and/or specific seasonal research cruises ${ }^{41}$. To characterize natural variability along the Chilean coast, we have compiled and plotted all the temporal time series data available for different coastal habitats along with a frequency analysis of regional $p_{\mathrm{CO}_{2}}$ data collected over at least one year at different time intervals (daily, weekly, biweekly, monthly and so on; Supplementary Table 1). The data set created captures a wide environmental spectrum averaged for the upper $10 \mathrm{~m}$ of the water column and includes coastal upwelling areas, river plumes, river-influenced upwelling areas, estuarine ecosystems, river-influenced fjords and tidal inlets (Fig. 1). 
All geographic sites selected for these $p_{\mathrm{CO}_{2}}$ observation programmes correspond to areas far from the direct effects of human activities that could lead to high $p_{\mathrm{CO}_{2}}$ levels resulting from respiration of anthropogenic organic matter (Supplementary Table 1).

Autocorrelation analyses were carried on raw data using the longest continuous records of $p_{\mathrm{CO}_{2}}$ observations available from contrasting environmental settings, using the xcorr function with MATLAB R2013A. Significant differences $(P<0.01)$ between autocorrelation functions were observed at lag-1 using a Bonferroni correction for multiple comparisons.

Data analysis of biological response experiments. In the present meta-analysis, we have compiled all the published information available with the aim of both characterizing the reaction norm and evaluating the effect of high $p_{\mathrm{CO}_{2}}$ levels (that is, from 910 to $1,500 \mu \mathrm{atm}$ ) on several physiological traits, such as ingestion, respiration, larval survival, calcification and growth in marine organisms along the HCS off Chile (Table 1). All this information came from studies that used individuals from populations inhabiting different geographic regions along the Chilean coast, each with contrasting environmental $p_{\mathrm{CO}_{2}}$ levels and encompassing different habitat such as coastal ocean, estuaries, river-plume areas and tidal inlets (Table 1). Furthermore, all these studies were conducted between 2009 and 2012 using the same semi-automatic system designed for long-term seawater carbonate chemistry manipulation ${ }^{42}$. Low $p_{\mathrm{CO}_{2}}$ conditions for all these experiments were nearly atmospheric $p_{\mathrm{CO}_{2}}$ conditions at that time period (that is, 347-398 $\mu \mathrm{atm}$ ). They include several taxa, such as the small planktonic copepod A. tons $a^{43}$, newly hatched planktonic larvae and juveniles of the benthic gastropod Concholepas concholepas ${ }^{29,30,44}$, adult individuals of the intertidal mussel Perumytilus purpuratus ${ }^{30}$ and juveniles of the intertidal/subtidal mussel Mytilus chilensis ${ }^{31}$.

To evaluate the mean effect of high $p_{\mathrm{CO}_{2}}$ conditions on different physiological traits among taxa, we estimated the ln-transformed response ratio ${ }^{11}$ as

$$
\operatorname{LnRR}=\ln \left(\bar{X}_{\mathrm{E}}\right)-\ln \left(\bar{X}_{\mathrm{C}}\right)
$$

where $\bar{X}_{\mathrm{E}}$ and $\bar{X}_{\mathrm{C}}$ are the mean responses in the experimental and control treatments. A positive ln-transformed response ratio indicates a positive effect and a negative value indicates a negative effect.

Data availability. Data on the experimental response of target marine organisms under laboratory conditions can be obtained from the Ocean Acidification International Coordination Center (OA-ICC) data compilation site ${ }^{45}$ through Pangaea (http://www.pangaea.de/) and is open access to everyone. Any data used in this paper can be obtained by contacting the corresponding author.

\section{Received 8 June 2016; accepted 16 January 2017;} published 13 March 2017

\section{References}

1. Caldeira, K. \& Wickett, M. Ocean model predictions of chemistry changes from carbon dioxide emissions to the atmosphere and ocean. J. Geophys. Res. 110, C09S04 (2005)

2. Orr, J. C. et al. Anthropogenic ocean acidification over the twenty-first century and its impact on calcifying organisms. Nature 437, 681-686 (2005).

3. Zalasiewicz, J., Williams, M., Haywood, A. \& Ellis, M. The Anthropocene: a new epoch of geological time? Phil. Trans. R. Soc. A. 369, 835-841 (2011).

4. Gattuso, \& J. P. et al. Contrasting futures for ocean and society from different anthropogenic $\mathrm{CO}_{2}$ emissions scenarios. Science 349, 49-55 (2015).

5. Magnan, A. K. et al. Implications of the Paris agreement for the ocean. Nat. Clim. Change 6, 732-735 (2016).

6. Bowman, H. I. Applying organized scepticism to ocean acidification research ICES J. Mar. Sci. 73, 529-536 (2016).

7. Doney, S. C. The growing human footprint on coastal and open-ocean syndrome? Understanding anthropogenic impacts on seawater $\mathrm{pH}$. Science 328, 1512-1516 (2010).

8. Fabry, V. J., Seibel, B. A., Feely, R. A. \& Orr, J. C. Impacts of ocean acidification on marine fauna and ecosystem processes. ICES J. Mar. Sci. 65, 414-432 (2008)

9. Cornwall, C. E. \& Hurd, C. L. Experimental design in ocean acidification research: problems and solutions. ICES J. Mar. Sci. 73, 572-581 (2016).

10. Barry, J. P., Hall-Spencer, J. M. \& Tyrrell, T. in Guide to Best Practices for Ocean Acidification Research and Data Reporting (eds Riebesell, U., Fabry, V. J., Hansson, L. \& Gattuso, J. P.) 53-66 (Publications Office of the European Union, 2010).

11. Kroeker, K., Kordas, R., Crim, R. \& Singh, G. Meta-analysis reveals negative yet variable effects of ocean acidification on marine organisms. Ecol. Lett. 13, 1419-1434 (2010)

12. Waldbusser, G. G. \& Salisbury, J. E. Ocean acidification in the coastal zone from an organism's perspective: multiple system parameters, frequency domains, and hábitats. Annu. Rev. Mar. Sci. 6, 221-247 (2014).
13. Feely, R. A., Sabine, C. L., Hernández-Ayon, J. M, Ianson, D. \& Hales, B. Evidence for upwelling of corrosive "acidified" water onto the continental shelf. Science 320, 1490-1492 (2008).

14. Salisbury, J., Green, M., Hunt, C. W. \& Campbell, J. Coastal acidification by rivers: a threat to shellfish? Eos 89, 513-528 (2008).

15. Cai, W.-J. et al. Acidification of subsurface coastal waters enhanced by eutrophication. Nat. Geosci. 4, 766-770 (2011).

16. Hoffman, G. E. et al. High-frequency dynamics of ocean pH: a multiecosystem comparison. PLoS ONE 6, e28983 (2011).

17. Reum, J. C. P. et al. Interpretation and design of ocean acidification experiments in upwelling systems in the context of carbonate chemistry co-variation with temperature and oxygen. ICES J. Mar. Sci. 73, 582-595 (2016).

18. Duarte, C. M. et al. Is ocean acidification an openocean syndrome? Understanding anthropogenic impacts on seawater pH. Estuaries Coasts 36, 221-236 (2013).

19. Dorey, N., Lancon, P., Thorndyke, M. \& Dupont, S. Assessing physiological tipping point for sea urchin larvae exposed to a broad range of $\mathrm{pH}$. Glob. Change Biol. 19, 3355-3367 (2013).

20. Ventura, A., Schulz, S \& Dupont, S. Maintained larval growth in mussel larvae exposed to acidified under-saturated seawater. Sci. Rep. 6, 23728 (2016)

21. Thor, P. \& Dupont, S. Transgenerational effects alleviate severe fecundity loss during ocean acidification in a ubiquitous planktonic copepod. Glob. Change Biol. 21, 2261-2271 (2015)

22. Kapsenberg, L., Kelley, A. L., Shaw, E. C., Martz, T. R. \& Hofmann, G. E. Seasonal $\mathrm{pH}$ variability in near-shore Antarctica in the present and future. Sci. Rep. 5, 9638 (2015).

23. Kapsenberg, L. \& Hofmann, G. E. Regional to local influences on daily to inter-annual $\mathrm{pH}$ variability in the northern Channel Islands, California, USA Limnol. Oceanogr. 61, 953-968 (2016).

24. McElhany, P. \& Busch, D. S. Appropriate $p_{\mathrm{CO}_{2}}$ treatments in ocean acidification experiments. Mar. Biol. 160, 1807-1812 (2012).

25. Angilletta, M. J. Thermal Adaptation: A Theoretical and Empirical Synthesis (Oxford Univ. Press, 2009).

26. Pérez, C. A. et al. Influence of climate and land use in carbon biogeochemistry in lower reaches of rivers in central-southern Chile: implications for the carbonate system in river-influenced rockyshore environments. J. Geophys. Res.: Biogeosci. 120, 673-692 (2015).

27. Calosi, P. et al. Adaptation and acclimatization to ocean acidification in marine ectotherms: an in situ transplant experiment with polychaetes at a shallow $\mathrm{CO}_{2}$ vent system. Phil. Trans. R. Soc. B 368, 20120444 (2013)

28. Bednarsêk, N. et al. Limacina helicina shell dissolution as an indicator of declining habitat suitability owing to ocean acidification in the California Current Ecosystem. Proc. R. Soc. B 281, 20140123 (2014).

29. Lardies, M. A. et al. Differential response to ocean acidification in physiological traits of Concholepas concholepas populations. J. Sea Res. 90 127-134 (2014).

30. Vargas, C. A. et al. $\mathrm{CO}_{2}$-driven ocean acidification disrupts the filter feeding behavior in Chilean gastropod and bivalve species from different geographic localities. Estuaries Coasts 38, 1163-1177 (2015).

31. Duarte, C. et al. Intraspecific variability in the response of the edible mussel Mytilus chilensis (Hupe) to ocean acidification. Estuaries Coasts 38, 590-598 (2015).

32. Hoffman, A. A. \& Sgrò, C. M. Climate change and evolutionary adaptation. Nature 470, 479-485 (2011).

33. Wernberg, T. et al. An extreme climatic event alters marine ecosystem structure in a global biodiversity hotspot. Nat. Clim. Change 3, 78-82 (2013).

34. Applebaum, S. L., Pan, T.-C. F., Hedgecock, D. \& Manahan, D. T. Separating the nature and nurture of the allocation of energy in response to global change. Integr. Comp. Biol. 54, 284-295 (2014).

35. Boyd, P. W. et al. Biological responses to environmental heterogeneity under future ocean conditions. Glob. Change Biol. 22, 2633-2650 (2016).

36. Beaman J. E., White, C. R. \& Seebacher, F. Evolution of plasticity: mechanistic link between development and reversible acclimation. TREE 31, 237-249 (2016).

37. Bordeau, P. E. et al. What can aquatic gastropods tell us about phenotypic plasticity? A review and meta-analysis. Heredity 115, 312-321 (2015).

38. Thiel, M. et al. The Humboldt Current System of northern and central Chile: oceanographic processes, ecological interactions and socioeconomic feedback Oceanogr. Mar. Biol. 45, 195-344 (2007).

39. Torres, R. et al. Air-sea $\mathrm{CO}_{2}$ fluxes along the coast of Chile: from $\mathrm{CO}_{2}$ outgassing in central northern upwelling waters to $\mathrm{CO}_{2}$ uptake in southern Patagonian fjords. J. Geophys. Res. 116, C09006 (2011).

40. Mayol, E., Ruiz-Halpern, S., Duarte, C. M., Castilla, J. C. \& Pelegrí, J. L. Coupled $\mathrm{CO}_{2}$ and $\mathrm{O}_{2}$-driven compromisos to marine life in summer along the Chilean sector of the Humboldt Current System. Biogeosciences 9, 1183-1194 (2012). 
41. Vargas et al. Riverine and corrosive upwelling waters influences on the carbonate system in the coastal upwelling area off central Chile: implications for coastal acidification events. J. Geophys. Res.: Biogeosci. 121, 1468-1483 (2016).

42. Torres, R. et al. Evaluation of a semi-automatic system for long-term seawater carbonate chemistry manipulation. Rev. Chil. Hist. Nat. 86, 443-451 (2013).

43. Aguilera, V. A., Vargas, C. A., Lardies, M. A. \& Poupin, M. J. Adaptive variability to low-pH river discharges in Acartia tonsa and stress responses

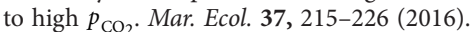

44. Manríquez, P. H. et al. Effects of ocean acidification on larval development and early post-hatching traits in Concholepas concholepas (loco). Mar. Ecol. Prog. Ser. 514, 87-103 (2014).

45. Yang, Y., Hansson, L. \& Gattuso, J.-P. Data compilation on the biological response to ocean acidification: an update. Earth Syst. Sci. Data 8, 79-87 (2016).

\section{Acknowledgements}

This work was supported by the Millennium Nucleus Center for the Study of Multiple-Drivers on Marine Socio-Ecological Systems (MUSELS) funded by MINECON NC120086 and the Millennium Institute of Oceanography (IMO) funded by MINECON IC120019. Previous and additional support from grants FONDECYT $1130254,1060938,1140938,11400092$ and 11130052 (RELOAD) is also acknowledged.
We acknowledge L. Saavedra for $p_{\mathrm{CO}_{2}}$ data sharing through grant FONDECYT 3150392. S.D. is funded by the Centre for Marine Evolutionary Biology (CeMEB; http://www. cemeb.science.gu.se/) and supported by a Linnaeus grant from the Swedish Research Councils VR and Formas.

\section{Author contributions}

All authors provided input into data availability and preliminary discussions. C.A.V. led the drafting of the text with main contributions in the same order from S.D., B.R.B., S.W., N.A.L., M.A.L., C.D., P.H.M. and V.M.A. C.A.V. carried out data analysis and the main structure of the study.

\section{Additional information}

Supplementary information is available for this paper.

Reprints and permissions information is available at www.nature.com/reprints. Correspondence and requests for materials should be addressed to C.A.V.

How to cite this article: Vargas, C. A. et al. Species-specific responses to ocean acidification should account for local adaptation and adaptive plasticity. Nat. Ecol. Evol. 1, 0084 (2017).

\section{Competing interests}

The authors declare no competing financial interests. 